Atmospheric composition and micro-climate in the Alhambra monument, Granada (Spain), in the context of preventive conservation

This article has been downloaded from IOPscience. Please scroll down to see the full text article.

2012 IOP Conf. Ser.: Mater. Sci. Eng. 37012002

(http://iopscience.iop.org/1757-899X/37/1/012002)

View the table of contents for this issue, or go to the journal homepage for more

Download details:

IP Address: 146.175.13.243

The article was downloaded on 25/07/2012 at 10:16

Please note that terms and conditions apply. 


\title{
Atmospheric composition and micro-climate in the Alhambra monument, Granada (Spain), in the context of preventive conservation
}

\author{
B Horemans ${ }^{\mathrm{a}, 1}$, O Schalm ${ }^{\mathrm{a}}, \mathrm{K}_{\mathrm{De}} \mathrm{Wael}^{\mathrm{a}}, \mathrm{C} \mathrm{Cardell}^{\mathrm{c}}$ and R Van Grieken ${ }^{\mathrm{a}}$ \\ ${ }^{a}$ University of Antwerp, Universiteitsplein 1, BE-2610 Antwerp, Belgium; ${ }^{b}$ \\ Email: benjamin.horemans@ua.ac.be
}

\begin{abstract}
The world famous Alhambra monument in Granada, Southern Spain, listed as UNESCO world cultural heritage since 1984, represents probably the most beautiful example of Islamic art and architecture from the Middle Ages in Europe. It is visited by ca. 2 million people annually. Granada is situated in a natural basin, surrounded by mountains with altitudes up to $3500 \mathrm{~m}$. Due to this topography and the prevailing low wind speeds, pollution-derived and especially traffic-derived particulate matter often accumulates in the urban air. In order to evaluate the potential conservation risks from the surrounding air, the atmospheric composition in the Alhambra monument was evaluated. Indoor temperature and relative humidity fluctuations were evaluated for their potential degenerative effects. Furthermore, the atmospheric composition in the Alhambra was analyzed in terms of inorganic gases $\left(\mathrm{NO}_{2}, \mathrm{SO}_{2}\right.$, $\mathrm{O}_{3}$, and $\mathrm{NH}_{3}$ ) and black carbon. It was found that the open architecture protected the indoor environments from developing a potentially harmful microclimate, such as the build-up of humidity resulting from the huge number of daily tourists. On the downside, the strong ventilation made the indoor air hardly different from outdoor air, as characterized by strong diurnal temperature and relative humidity gradients and high traffic-derived pollutant levels.
\end{abstract}

\section{Introduction}

The consequences of atmospheric pollution are some of the biggest challenges in modern times. Historical pollution episodes such as the Meuse valley fog (Belgium) in 1930 and the London fog in 1952 made people aware of the causal relationship between air pollution and increased morbidity and mortality $[1,2]$. The negative effects of atmospheric pollution do not stop with our health, but also affect the natural balance of many remote areas [3-5], and are directly responsible for climate change phenomena [6-8]. Besides these environmental and health issues, air pollution also accelerates the attack of our tangible cultural heritage.

It is important to know how atmospheric pollution deposits on heritage structures and how it will affect material properties such as morphology, composition, strength, and aesthetic appearance. Atmospheric gases such as $\mathrm{SO}_{2}, \mathrm{NO}_{2}$ and $\mathrm{O}_{3}$ are often studied in relation to preventive conservation due to their corrosive effects on many artwork materials [9-11]. Deposition of particulate pollution, also known as soiling, leads to blackening of heritage materials. Blackening is caused by the formation of a thin layer of atmospheric particles which absorb visible light on the surface of diverse construction and decorative materials. Previous publications already reported in detail on the chemical

\footnotetext{
${ }^{1}$ To whom any correspondence should be addressed.
} 
composition of particulate pollution inside the Alhambra monument [12, 13]. It was found that black carbon (BC) was one of the dominant components of airborne particles with a diameter below $1 \mu \mathrm{m}$. Although many atmospheric particles are able to absorb in the visible light spectrum, $\mathrm{BC}$ is by far the main component which induces blackening. In addition, soiling of monuments also leads to direct deterioration of heritage materials, due to their interaction with hygroscopic salts [14-17], which also represent a large fraction of the aerosol in the Granada city and the local surroundings of the Alhambra monument [13].

It is evident that the atmospheric degradation of our cultural heritage is extremely complex, depending on many atmospheric conditions and material properties. Nevertheless, it is well known that the atmospheric properties such as climate and composition have a considerable impact on the heritage environment. Stable atmospheric conditions and low pollutant levels are most favorable for the conservation of our cultural heritage. However, in real museum and monument environments, one often encounters conditions which are far from ideal. At the Alhambra, the effects of the semi-open architecture and the huge number of daily tourists on the atmospheric composition, temperature and relative humidity $(\mathrm{RH})$ inside the palaces are considered to be an important threat. This study is a first attempt to evaluate these deterioration risks at the monumental complex of the Alhambra and Generalife in Granada, by analyzing the micro-climate and the pollution load of the local atmosphere. The results could help conservators with formulating targeted strategies with respect to atmospheric degradation.

\section{Experimental}

Detailed information on the monument, sampling locations, instrumentation and analytical performance data for the present study were outlined in earlier publications and are not repeated here. Only a brief summary of the methodology is given here. Readers looking for more detail are referred to the literature [12].

The Alhambra was a fortified palatine city constructed from the $11^{\text {th }}$ to the $15^{\text {th }}$ century, comprising a fortress, 23 towers, gates, mosques, spas and 7 palaces. The palaces in the monument were built during the Nasrid dynasty (1238-1492). The Nasrid palaces are composed of a complex combination of rooms. Apart from the Royal Baths which are closed from the outdoor environment, all rooms are in direct contact with the outdoor climate. Pollutants, temperature and relative humidity might affect the elaborate polychromed stucco (gypsum-based decoration), marble, wooden ceilings and tiling ornaments inside the rooms. For the semi-open rooms, decorations and volumes of the rooms can be significantly different. Therefore, three rooms (from diverse palaces) and one outdoor reference location $(\mathrm{O})$ have been selected in order to evaluate the impact of the pollution and climatic conditions on the complete complex. Inside the Nasrid palaces of the Alhambra, the 'Room of the Two Sisters' (P1), the 'Royal Baths' (P2) and the 'Ambassadors Hall' (P3) were selected as study areas. Atmospheric pollutants at each of these locations were investigated on a weekly basis, for a total period of three weeks ( $15^{\text {th }}$ of June until $5^{\text {th }}$ of July 2009).

Every week, parallel samples of major inorganic atmospheric gases $\left(\mathrm{NH}_{3}, \mathrm{SO}_{2}, \mathrm{NO}_{2}\right.$, and $\left.\mathrm{O}_{3}\right)$ were collected at all locations simultaneously, by means of passive sampling devices. The mean atmospheric concentration of the gases was calculated from the sampled mass, sampling time and temperature-corrected sampling rate, as described by the manufacturer of the sampling devices (Radiello, Padova, Italy). Ion chromatography (for $\mathrm{NH}_{3}, \mathrm{NO}_{2}$ and $\mathrm{SO}_{2}$ ) and visible light spectrometry (for $\mathrm{O}_{3}$ ) were used for analyzing the absorbed mass of each gas. The concentration of $\mathrm{BC}$ was monitored in a semi-continuous fashion (10 min interval) with a portable aethalometer (AE42, Magee Scientific, Berkeley, CA, USA). The instrument was moved each week to a different location inside the palaces (P1, P2, and P3).

The micro-climate of each room was analyzed with calibrated ATX-11 data loggers (ATAL, Purmerend, The Netherlands) which registered thermo-hygrometric parameters every $15 \mathrm{~min}$. These instruments measure the air temperature and RH with a built-in platinum thermo-resistance sensor (Pt1000, accuracy: $0.4^{\circ} \mathrm{C}$ ) and a thin-film capacitive sensor (accuracy: $2.5 \%$ in the range of $5-95 \%$ 
RH), respectively. For comparison, an outdoor reference location was selected to be monitored simultaneously with the indoor locations during a full year.

\section{Results}

\subsection{Meteorological fluctuations}

Meteorological conditions affect buildings in several ways. Not only do they influence the rate with which pollutants react with the surface of construction/decorative materials of buildings and the biological activity of micro-organisms, but they also induce material stress through processes of dilatation and contraction. In our study, we expected that the huge numbers of daily tourists visiting the Nasrid palaces of the Alhambra would affect the micro-climate of the diverse rooms, especially the humidity inside the palaces. Moreover, the semi- open architecture of this monument barely buffers the strong outdoor meteorological fluctuations, thereby exposing the unique polychromes and other artwork such as wooden ceilings and tiling to (harsh) outdoor conditions.

The collected time series samples from the three rooms and the outdoor reference locations were very similar. Therefore, the potential danger of the meteorological conditions was analyzed by evaluating the micro-climate at the reference location. The yearly average temperature and $\mathrm{RH}$ were found to be $17 \pm 8^{\circ} \mathrm{C}$ (from -1.2 to $33.1^{\circ} \mathrm{C}$ ) and $54 \pm 19 \%$ (from 28 to $78 \%$ ), respectively (figure 1). The results of about one year showed only two days (January $9^{\text {th }}$ and $10^{\text {th }}$ ) with freezing temperatures during the night ( $\sim 8$ hours). Moreover, temperature never reached the dew point, so condensation on cold walls did not occur. As for RH, about $15 \%$ of the year was registered with values above $75.3 \%$ (deliquescence point of $\mathrm{NaCl}$ crystals), especially in the period from December to February. Long wet periods lasted about 10 to 60 hours and were interrupted with drier $(\leq 75 \% \mathrm{RH})$ periods or shorter wet periods. The isolines in figure 1 show how temperature and RH fluctuate throughout the day and the year. The average seasonal contribution was estimated by fitting a sinusoidal function to the monthly averaged data (not shown). It was responsible for a total annual temperature and RH change of $20.2^{\circ} \mathrm{C}$ and $42 \%$, respectively. The average diurnal fluctuation, as estimated from a sinusoidal fit to the hourly averaged data (not shown), showed a total daily change of $4^{\circ} \mathrm{C}$ and $7 \%$, respectively.
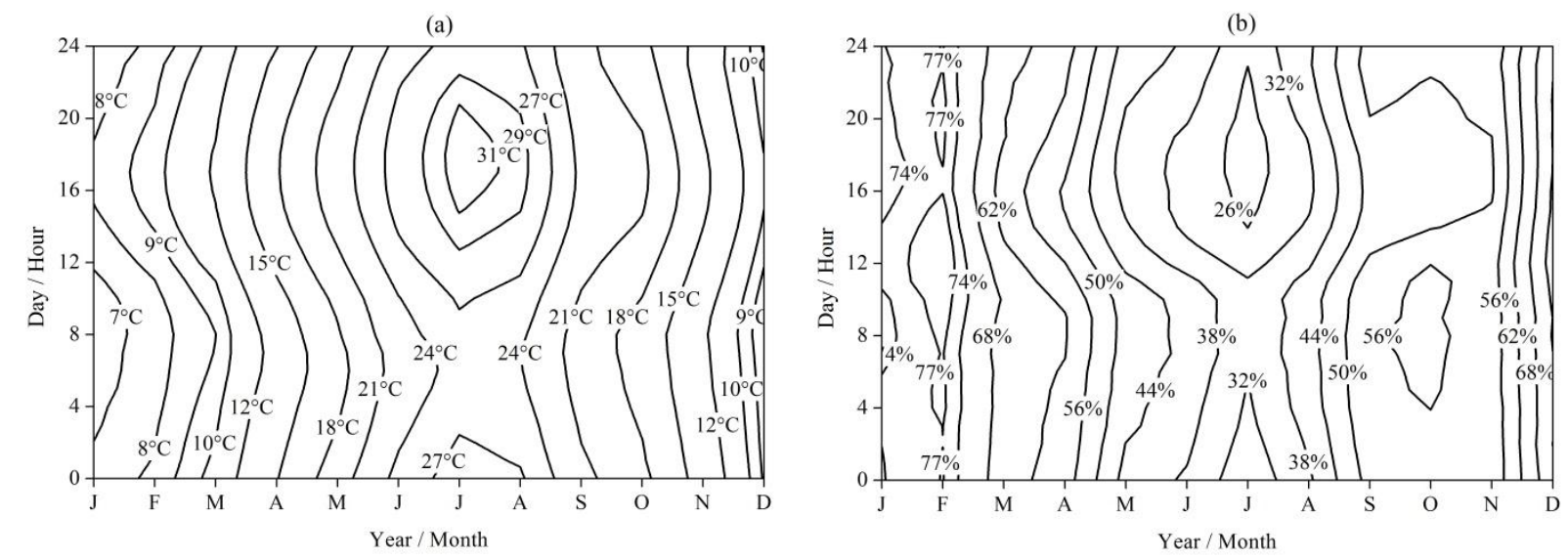

Figure 1. Seasonal and diurnal fluctuation of (a) air temperature and (b) RH at the reference site. 


\subsection{Gaseous atmospheric composition}

Summer in Granada is characterized by warm and dry days with intense solar radiation and almost no cloud cover. In the first week of the survey, the $\mathrm{O}_{3}$ concentrations reached the European alarm threshold of $114 \mathrm{ppb}$, while, during the second and the third week, $\mathrm{O}_{3}$ levels were below the European warning threshold of $85 \mathrm{ppb}$ (figure 2a). This reduction resulted from a developing low pressure system over the Atlantic Ocean, which disturbed the stable high pressure field maintained over the European continent during the first week. This made the ruling Mediterranean air transport to be gradually replaced by Atlantic air parcels coming from high altitudes (figure 3), which injected fresh air into the city. This change in atmospheric conditions drastically reduced the $\mathrm{O}_{3}$ formation and accumulation of photochemical smog. Despite this meteorological change, $\mathrm{NO}_{2}$ and $\mathrm{NH}_{3}$ were almost constant over the campaign (6-14 ppb), reflecting the constant local traffic source. $\mathrm{SO}_{2}$ concentrations in and around the Nasrid palaces were extremely low $(<0.45 \mathrm{ppb})$ and didn't exceed the quantification limit of the sampling method (1 ppb). This is probably due to the strong photoactive oxidation of $\mathrm{SO}_{2}$, resulting in fast gas-to-particle conversion of sulphur pollutants [18].

At the outdoor reference location $(\mathrm{O}), \mathrm{O}_{3}$ concentrations ranged from 61-111 ppb and averaged around $79 \pm 23 \mathrm{ppb}$ (figure $2 \mathrm{~b}$ ). Indoors $(\mathrm{P} 1, \mathrm{P} 2, \mathrm{P} 3)$, the reactive $\mathrm{O}_{3}$ pollutant is quickly removed from air by deposition on walls and ceilings. An indoor environment which is somehow shielded from outdoor air will therefore have low $\mathrm{O}_{3}$ levels, since the input of new $\mathrm{O}_{3}$ does not compensate for the loss due to deposition. This could be seen from the $\mathrm{O}_{3}$ levels at the more isolated $\mathrm{P} 2$ location, which were on average almost two times lower compared to outdoor air. Concentrations at P1 were only slightly decreased, while those at P3 were found to be similar compared to ambient air (figure 2b). This illustrates how the semi-open architecture of the palaces makes the interior highly susceptible for exposure to aggressive pollutants such as $\mathrm{O}_{3}$. Concentrations for $\mathrm{NO}_{2}$ inside the palaces were slightly less than outdoors, while for $\mathrm{NH}_{3}$ the opposite was observed.
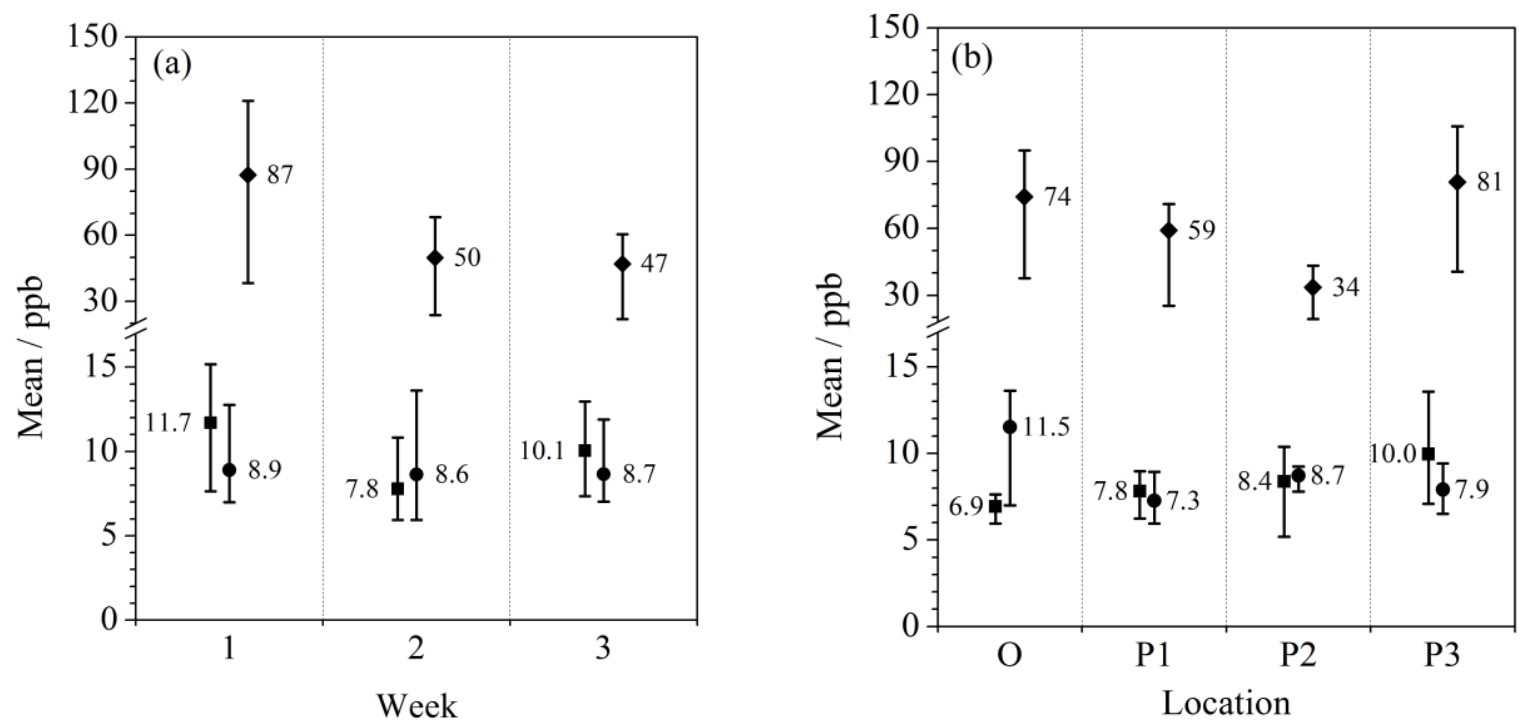

Figure 2. Atmospheric concentration of major inorganic gases averaged according to (a) sampling week (b) location in the monument. Bars represent concentration range. Diamond: $\mathrm{O}_{3}$; Circle: $\mathrm{NO}_{2}$; Square: $\mathrm{NH}_{3}$. 

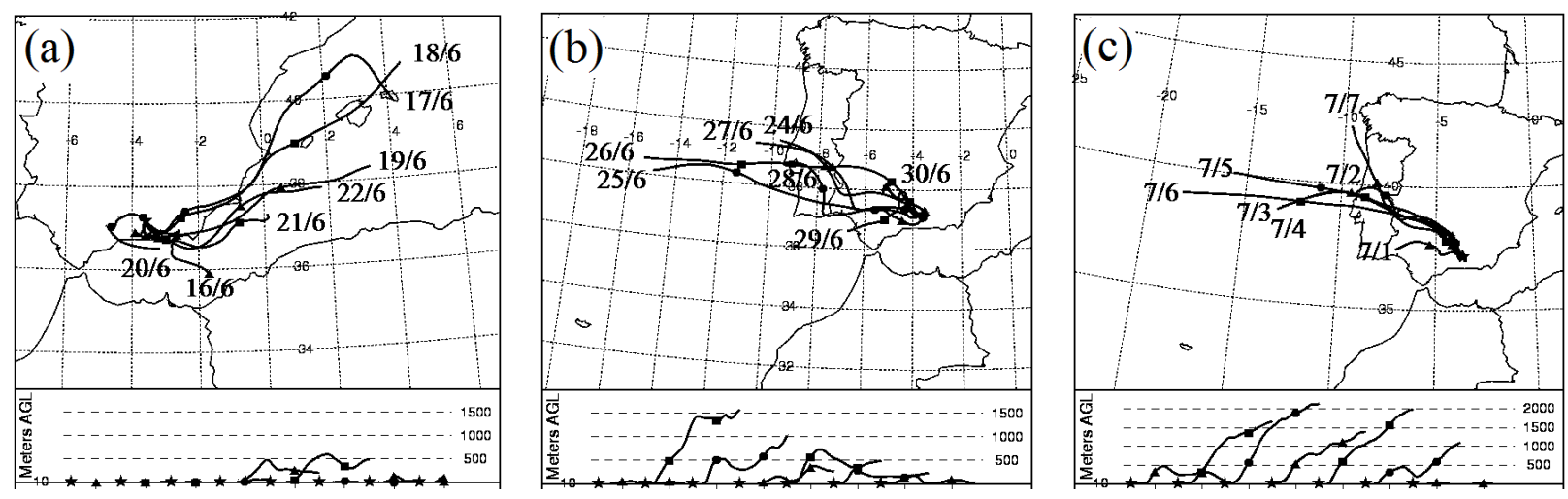

Figure 3. Daily air mass backward trajectories during the (a) first, (b) second, and (c) third week of the sampling campaign, as calculated by the HYSPLIT model with GDAS meteorological data $[19,20]$. Trajectories arrive at the Alhambra $\left(37.18^{\circ}\right.$ North, $3.59^{\circ}$ West) on $12 \mathrm{pm}$ UTC of the indicated dates. Below each map, the vertical trajectories are indicated in units of meters above ground level (AGL).

\subsection{Black carbon}

From the gaseous atmospheric composition, it is clear that the air in the palaces was hardly different from outdoor air. Therefore, it could be expected that the amount of $\mathrm{BC}$ also strongly depends on the outdoor conditions. The typical daily pattern of $\mathrm{BC}$ inside the palaces is shown in figure 4 . It can be seen how the background concentration of $\mathrm{BC}$ is fairly constant, around a value of 1 to $1.5 \mu \mathrm{g} \mathrm{m}^{-3}$. However, at the start of every day ( 7 to $8 \mathrm{am}$ ), BC concentrations increased steeply to a maximal average concentration of $6 \mu \mathrm{g} \mathrm{m}^{-3}$ in a period of only 1-2 hours (maximum around $10 \mathrm{am}$ ), after which it dropped slowly. These results illustrate how the Nasrid palaces are directly suffering from exposure to traffic-derived pollutants produced in the local urban area of Granada.

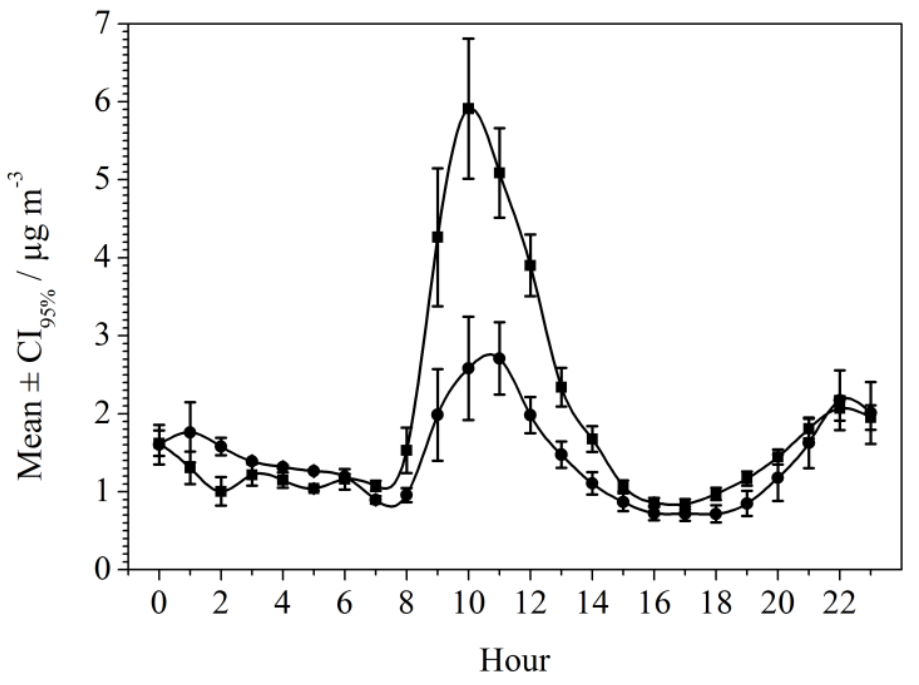

Figure 4.Average daily pattern for black carbon $(\mathrm{BC})$ inside the Nasrid palaces. Bars represent a 95\% confidence interval. Square: Monday to Friday; Circle: Saturday to Sunday.

\section{Discussion}

The collected meteorological time series samples from the three rooms and the outdoor reference locations in the Alhambra monument were very similar. Seasonal and diurnal gradients were present inside the rooms, suggesting that the indoor air is regularly refreshed by outdoor air. Only for the Royal Baths (P2) the impact of outdoor meteorological conditions was rather small, suggesting that 
the outdoor air diffuses slowly into these rooms. Since the environmental conditions for outdoor and indoor air are so similar, it is difficult to discern the influence of daily tourists on the monument's microclimate, probably due to the fast replenishment of air inside the semi- open rooms, which blows out any humidity excess. However, the outdoor meteorological fluctuations can be considered more aggressive to the wooden and stucco painted decorations as compared to typical conditions in museum environments, which are often equipped with instrumentation for climate control.

The major difficulty of the present study is the semi-open architecture of the monument, and hence, nearly identical indoor and outdoor conditions, while ideal meteorological conditions for the conservation of heritage objects are usually reported for confined indoor environments. It is suggested that mixed objects should be stored at temperatures between 19 and $24^{\circ} \mathrm{C}$ and at a $\mathrm{RH}$ ranging from 45 to $60 \%$ [21]. The annual average temperature at the Alhambra was found to be slightly below this ideal indoor temperature range $\left(17^{\circ} \mathrm{C}\right)$, while $\mathrm{RH}$ seemed to be acceptable $(54 \%)$. Inside the studied rooms material damage due to freeze-thaw cycles and condensation on cold walls was found to be negligible. Also, damage due to crystallization-dissolution cycles of salts inside porous materials [22] was limited, since the RH throughout the year was generally below $75.3 \%$, i.e. the deliquescence point of $\mathrm{NaCl}$. Only in the period from December to February, the RH exceeded the critical limit of $75 \%$ on a regular basis (figure 1).

However, the most disastrous effect of meteorological parameters to objects of art in the Alhambra is the rate with which they fluctuate. The fast and unpredictable changes in temperature and $\mathrm{RH}$ was decomposed in a factor describing seasonal, diurnal and weather effects. While the former two are periodic fluctuations depending on solar radiation, the latter is the result of (rapid) changes in meteorological conditions.

In general, linear temperature and $\mathrm{RH}$ gradients not exceeding $1{ }^{\circ} \mathrm{C}$ and $5-10 \%$ per day, respectively, are considered as acceptable. Seasonal gradients occur gently and were found to be maximally $0.18^{\circ} \mathrm{C}$ and $0.34 \%$, respectively. Diurnal cycles were characterized by strong temperature and RH changes due to the particular topography of the Granada area, which is situated in a natural basin surrounded by mountains with altitudes up to $3500 \mathrm{~m}$. Inside the Nasrid palaces, maximum temperature gradients in the period from November until March ranged from 1.7 to $3.1^{\circ} \mathrm{C}_{\text {day }}{ }^{-1}$, while RH was almost constant throughout the day (figure 1). In spring until late summer (April until October), maximum diurnal temperature gradients ranged from 4.8 to $6.1^{\circ} \mathrm{C}_{\text {day }}{ }^{-1}$, while $\mathrm{RH}$ gradients were $9.4-12.8 \%$ day $^{-1}$. Especially for materials with a short response time (hours), such as paint layers, such changes might be harmful since they are sensitive to expansion and shrinkage of the surface material [23]. For materials with a longer response time (few days), such as wooden objects with more than $1 \mathrm{~cm}$ thickness, high frequency changes occur probably too fast for the object to adapt to the new conditions. The most dangerous phenomenon is probably the change in weather conditions. They are slow enough, so materials can adapt themselves to the environment, but they are fast enough to cause material stress, and hence, structural damage [24].

During the analysis campaigns, there was considerable air flow through the semi-open rooms, which blows out any humidity and gases produced by the visitors. However, the strong ventilation also results in exposure to pollutant levels which are typically found at outdoor environments. The composition of typical museum atmospheres is generally found to be poor in gaseous pollutants, with levels for $\mathrm{O}_{3}, \mathrm{NO}_{2}$ and $\mathrm{SO}_{2}$ below $10 \mathrm{ppb}$, between 30 and $70 \mathrm{ppb}$ and less than a few ppb, respectively [25]. At the Alhambra monument, $\mathrm{O}_{3}$ levels were high inside the Nasrid palaces, especially during the first week of the survey. It is well known that $\mathrm{O}_{3}$ reacts with organic painting materials such as dyes, binders or surface coats, leading to the fading of color paint layers [26]. Since 1923 until recently, all polychromed carpentry in the Alhambra was treated with a mixture of linseed oil, turpentine and beeswax to protect it against deterioration [27]. Ironically, in a way, this organic mixture could have enhanced the fading of the colors due to reaction with $\mathrm{O}_{3}$. For the inorganic pigments of the polychrome stucco and carpentry artworks of the Alhambra, such as vermilion, red lead, malachite and azurite [27, 28], the effects of $\mathrm{O}_{3}$ are still unknown. Concentrations of $\mathrm{NO}_{2}$ and $\mathrm{SO}_{2}$ in the palaces 
were similar to those found at other museum environments [29]. These acidifying gases are found to corrode artwork upon deposition.

On the other hand, soiling of buildings is one of the major problems related to particulate pollution. Deposition of particles affects the aesthetic appearance of artwork, by absorbing incident light. BC is by far the strongest absorber of visible light of all the components in airborne particles. Reducing the deposition of these black particles on monuments is therefore a priority issue for many conservators. In the Alhambra palaces, indoor $\mathrm{BC}$ concentrations depended strongly on traffic conditions in the Granada area (figure 4). On average, the background concentration of $\mathrm{BC}$ was found to be around $1 \mu \mathrm{g}$ $\mathrm{m}^{-3}$. When considering an average indoor deposition rate of $0.03 \mathrm{~cm} \mathrm{~s}^{-1}$ for particles below $2.5 \mu \mathrm{m}$ [30], the background concentration accounts for a total soiling of $\sim 0.95 \mathrm{mg} \mathrm{BC} \mathrm{m}^{-2}$ year $^{-1}$. However, daily concentrations were raised on average by a factor of 3.5 above this background for a total period of 8 hours per day. Such an increase could enhance soiling by about $80 \%$, raising it up to $1.7 \mathrm{mg}$ BC $\mathrm{m}^{-2}$ year $^{-1}$. Since these calculations are based on the average BC concentration during three weeks, it must be stressed that the extrapolated deposition rates of one year should be treated with care. Nevertheless, it gives a rough quantitative estimate on the soiling due to black particles in the Alhambra, and shows how the blackening process could be diminished by simply reducing the BC emissions close to the monument.

\section{Conclusion}

The evaluation of atmospheric risks for indoor environments is usually made by comparing quantities such as average temperature, relative humidity and maximum concentrations of pollutants with threshold values. In the case of semi-open rooms exposed to the outdoor climate, such evaluation is much more complicated. It was anticipated that the huge number of tourists visiting the Alhambra monument could affect the climate in the Nasrid palaces. Nevertheless, the strong ventilation and open architecture of the palaces made temperature and RH hardly different from outdoor air, and prevented the build-up of high humidity, condensation and microbial activity. However, at the downside, indoor decorations of the monument are exposed to strong meteorological fluctuations. While seasonal variations are still acceptable, strong diurnal temperature gradients are believed to pose a risk to the conservation of the polychrome and wooden artwork all over the monument. Analogously, the atmospheric composition inside the palaces was almost identical to that of the outdoor air. This was especially true for $\mathrm{O}_{3}$, which was found with high (smog-like) concentrations. $\mathrm{BC}$ was also found at higher concentrations than one could tolerate in a cultural environment.

Recently, Granada City Hall is planning to help tourists to get more easily to the monument by allowing cars to drive through the Alhambra Park, crossing the 'Gate of the Pomegranates', located on a steep street. At present, the $\mathrm{BC}$ concentration close to the entrance of the park is about $2 \mu \mathrm{g} \mathrm{m}^{-3}$, and about $1 \mu \mathrm{g} \mathrm{m}^{-3}$ inside the Nasrid palaces of the Alhambra. However, if the street is opened for traffic in the future, the BC concentration is expected to rise up to $8 \mu \mathrm{g} \mathrm{m}^{-3}$ or even higher, as found at a similarly steep street with dense traffic in the nearby Albayzín quarter (world heritage site since 1984). Such decisions could have a considerable impact on the levels of $\mathrm{BC}$ and other vehicle derived pollutants such as $\mathrm{NO}_{2}, \mathrm{SO}_{2}$ and $\mathrm{O}_{3}$ inside the Nasrid palaces, with major implications for their future conservation and the enjoyment of visitors to this famous monument. By simply limiting the traffic in and around the monumental complex of the Alhambra and Generalife, soiling and blackening of this unique Muslim monument could be minimized, thereby cutting on the budget for conservation and restoration of the highly detailed polychromed wall and ceiling decorations.

\section{Acknowledgement}

The authors thank the research group RNM-179 (CICE, JA, Spain) and the 'Patronato de la Alhambra y Generalife' for making this research possible. Special thanks go to M. Urosevic and J. RomeroPastor for their help in data acquisition. The authors gratefully acknowledge the NOAA Air Resources Laboratory (ARL) for the provision of the HYSPLIT transport and dispersion model and the READY website (http://www.arl.noaa.gov/ready. html) used in this publication. 


\section{References}

[1] Nemery B, Hoet P H M and Nemmar A 2001 Lancet 357 704-8

[2] Logan W P D 1953 The Lancet 261 336-8

[3] Bencs L, Krata A, Horemans B, Buczynska A J, Dirtu A C, Godoi A F L, Godoi R H M, Potgieter-Vermaak S and Van Grieken R 2009 Atmos. Environ. 43 3786-98

[4] Bargagli R 2008 Sci. Total Environ. 400 212-26

[5] Fromberg A, Cleemann M and Carlsen L 1999 Chemosphere 38 3075-93

[6] Ramanathan V and Feng Y 2009 Atmos. Environ. 43 37-50

[7] Lee D S, Fahey D W, Forster P M, Newton P J, Wit R C N, Lim L L, Owen B and Sausen R 2009 Atmos. Environ. 43 3520-37

[8] Kondratyev K Y 1996 Energy Convers. Manage. 37 763-8

[9] Kontozova-Deutsch V, Godoi R H M, Worobiec A, Spolnik Z, Krata A, Deutsch F and Van Grieken R 2008 Microchim. Acta 162 425-32

[10] Gysels K, Delalieux F, Deutsch F, Van Grieken R, Camuffo D, Bernardi A, Sturaro G, Busse H-J r and Wieser M 2004 J. Cult. Herit. 4 221-30

[11] Godoi R H M, Kontozova V and Van Grieken R 2006 Atmos. Environ. 40 1255-65

[12] Horemans B, Cardell C, Bencs L, Kontozova-Deutsch V, De Wael K and Van Grieken R 2011 Microchem. J. 99 429-38

[13] Potgieter S, Horemans B, Anaf W, Cardell C and Van Grieken R 2012 J. Raman Spectrosc. In press. DOI 10.1002/jrs.4052

[14] Cardell C, Rivas T, Mosquera M J, Birginie J M, Moropoulou A, Prieto B, Silva B and Van Grieken R 2003 Earth Surf. Proc. Land. 28 1-14

[15] Cardell C, Delalieux F, Roumpopoulos K, Moropoulou A, Auger F and Van Grieken R 2003 Constr. Build. Mater. 17 165-79

[16] Cores. Consumption of oil-based products. 2008 [cited 201124 May]; Available from: http://www.cores.es.

[17] Rivas T, Prieto B, Silva B and Birginie J M 2003 Earth Surf. Proc. Land. 28 425-36

[18] Kelly T J, McLaren S E and Kadlecek J A 1989 Atmos. Environ. (1967) 23 1315-32

[19] Draxler R R and Rolph G D. HYSPLIT (HYbrid Single-Particle Langrangian Integrated Trajectory) Model access via NOAA ARL READY Website. Silver Spring, MD: NOAA Air Resources Laboratory; 2003 [cited 2011 6th June]; Available from: http://www.arl.noaa.gov/ready/hysplit4.html.

[20] Rolph G D. Real-time Environmental Applications and Display sYstem (READY) Website (http://www.arl.noaa.gov/ready/hysplit4.html). Silver Spring, MD: NOAA Air Resources Laboratory; 2003.

[21] Alcántara R. Standards in preventive conservation: meanings and applications. Report: ICCROM - International Centre for the Study of the Preservation and Restoration of Cultural Property 2002.

[22] George W S 2004 Cem. Concr. Res. 34 1613-24

[23] Camuffo D. Microclimate for Cultural Heritage. Amsterdam: Elsevier; 1998.

[24] Thomson G. The museum environment. Cornwall: Butterworth-Heinemann; 1986.

[25] Brimblecombe P 1990 Atmos. Environ. B-Urb. 24 1-8

[26] Whitmore P M and Cass G R 1988 Stud. Conserv. 33 29-40

[27] C. Cardell C, Rodriguez-Simon L, Guerra I and Sanchez-Navas A 2009 Archaeometry 21 637-57

[28] Cardell-Fernandez C and Navarrete-Aguilera C 2006 Stud. Conserv. 51 161-76

[29] Brimblecombe P 1990 Atmospheric Environment. Part B. Urban Atmosphere 24 1-8

[30] Lai A C K 2002 Indoor Air 12 211-4 